Revista Estudios, (37), 2018.

Diciembre 2018-Mayo 2019

ISSN 1659-3316

De Mézerville López Claire

V Sección: Educación e identidad

\title{
El diálogo desafiante: Cultura de Paz en lo referente a la Educación Sexual Costarricense.
}

Claire Marie de Mézerville López International Institute for Restorative Practices. IIRP Latinoamérica

clairedemezerville@iirp.edu https://orcid.org/0000-0002-8260-0872

Recibido: 3 de setiembre de 2018

Aceptado:2 de octubre de 2018

Resumen: Este documento presenta una reflexión sobre el impacto de los partidismos dirigidos a la identidad y la polarización de discursos sobre la educación sexual en la educación pública costarricense, así como la difusa conceptualización de la llamada "ideología de género" y las preocupaciones que plantea desde lo social comunitario. Se presenta una propuesta integradora de los principios necesarios para una educación sexual saludable, la cual fue ratificada por diez psicólogos costarricenses, entre ellos la autora. Una cultura de paz caracterizada por la participación de todas las partes involucradas, así como la capacidad para generar espacios seguros para el diálogo se hacen necesarias para enfrentar los temas delicados que atañen a la población menor de edad de Costa Rica.

Palabras clave: Educación Sexual; polarización; programas para la sexualidad y afectividad; adolescencia; mediación; cultura de paz; espacios seguros; diálogo

\section{The Challenging conversation: Peace culture regarding Costa Rican sexual education.}

Abstract: This article presents a reflexion about the impact of identity politics regarding the polarizing discourses about sexual education in Costa Rican public education. It also refers to the difuse conceptualization of the so called "gender ideology" and the concerns it raises from the comunity. An integrating proposal about the necesary principles for healthy sexual education is presented, which was

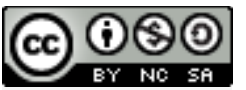

La Revista Estudios es editada por la Universidad de Costa Rica y se distribuye bajo una Licencia Creative Commons Atribución-NoComercial-CompartirIgual 3.0 Costa Rica. Para más información envíe un mensaje a revistaestudios.eeg@ucr.ac.cr. 
ratified by ten costa rican psychologist, including the author. A peace culture that builds on engaging all parties, as well as the capacity to open safe spaces for dialogue are fundamental to face the delicate issues that involve Costa Rican underage population.

Keywords: Sexual Education; adolescence; mediation; peace; culture; safe spaces; dialogue; identity politics

Introducción

La educación sexual costarricense se ha convertido en un tema de controversia en el último año. Tres elementos convergieron para polarizar la discusión sobre los programas del Ministerio de Educación Pública (MEP) para abordar el tema: la apertura programada para el 2018 del plan para décimo año (dirigido a estudiantes de aproximadamente de 15-16 años) sobre educación para la sexualidad y la afectividad (MEP, 2017; Periódico La Nación, 10 de abril de 2017). El segundo elemento fue la polémica y reciente campaña electoral para la presidencia de la República; el repudio de grupos nacionales a la llamada "ideología de género" ante el decreto ejecutivo D40422 del gobierno de la República (SCIJ, 2018) y exacerbado por la resolución de la Corte Interamericana de Derechos Humanos con respecto a la identidad de género, igualdad y no discriminación a parejas del mismo sexo (Corte IDH, 2017) y finalmente la visibilización del malestar de grupos de personas ante estos fenómenos sociales, quienes experimentan que estos acontecimientos atentan contra lo que llaman valores familiares y su subsecuente movilización en protestas a nivel nacional.

El objetivo de este artículo es visibilizar los peligros de un entorno político polarizado en la conversación sobre la educación sexual dirigida a la educación pública; ilustrar una postura integradora propuesta por un grupo de psicólogos y psicólogas costarricenses que llamamos a abrir vías de diálogo sobre este tema, así como sugerir reflexiones pertinentes para un abordaje desde una perspectiva

\section{(c) (i) (-)}

La Revista Estudios es editada por la Universidad de Costa Rica y se distribuye bajo una Licencia Creative Commons Atribución-NoComercial-CompartirIgual 3.0 Costa Rica. Para más información envíe un mensaje a revistaestudios.eeg@ucr.ac.cr. 
restaurativa por una cultura de paz, el cual se hace extremadamente necesario ante el panorama social en el que estamos inmersos.

Partidismos al corazón de nuestras identidades

Al actual panorama dividido debe sumarse un elemento clave: la incorporación de las redes sociales a la comunicación mediática. Las redes sociales y el internet no son las únicas variables en la realidad social actual, pero su influencia es significativa. Las redes sociales, por naturaleza, facilitan la divulgación de contenido. Lamentablemente, facilitan también la difusión sin filtros de contenido amarillista y noticias falsas. La escalada de agresividad en los discursos y la polarización a través del agrupamiento entre los iguales, así como la viralización de los mensajes más volátiles, medidos a través de "me gusta", "compartir" y cualquier reacción virtual en general. Es necesario entender que los algoritmos de dicha red tenderán a fortalecer las publicaciones más extremistas y agresivas, ya que son las que generan más respuesta, al igual que ofrecerán a la persona publicaciones y noticias que coincidan con los intereses que la persona ha manifestado (Harris, 2018). Las redes sociales pueden usarse para el bien o para el mal, pero su tendencia, en su naturaleza actual, será la de polarizar grupos.

En un contexto así, tomar partido se vuelve emocionalmente importante para muchas personas. Los partidismos dirigidos a la identidad parten de las posturas sobre temas polémicos que atañen a lo más preciado de las personas (Frum \& Sullivan, citados por Harris, 2018). Estos partidismos son exitosos para movilizar a las personas, ya que los motivan desde elementos esenciales a su ser, como su vida espiritual, su libertad de expresión, sus derechos civiles, entre otros.

Ahora bien, este fenónmeno no solo se da a través de redes sociales. En contextos donde las personas siguen de forma leal y partidaria a una agrupación,

\section{(ब) $(\otimes \odot)$}

La Revista Estudios es editada por la Universidad de Costa Rica y se distribuye bajo una Licencia Creative Commons Atribución-NoComercial-CompartirIgual 3.0 Costa Rica. Para más información envíe un mensaje a revistaestudios.eeg@ucr.ac.cr. 
causa o líder comunitario, político o religioso, existe el riesgo de que se agrupen con la noble intención de ser fieles al grupo de forma incondicional. Si bien, esto es parte de nuestra naturaleza humana (somos gregarios, nos ayudamos los unos a los otros y así sobreviviomos y nos desarrollamos), esto también tiene sus riesgos. Los partidismos dirigidos a la identidad tienen, entre sus efectos, la capacidad de agrupar "en contra de" como método de pertenencia y afiliación. En esta situación, incidentes violentos pueden aparecer, ya que se consideran medios justificables por un fin mayor y loable. Es la cara desagradable de nuestra lealtad.

Educación Sexual: Ideología de Género vs. Libertad de Culto

Los programas de educación sexual y para la afectividad propuestos por el Ministerio de Educación Pública iniciaron en el año 2012. Los planes fueron dirigidos al tercer ciclo, facilitados por profesores y profesoras de ciencias de séptimo, octavo y noveno año. Los programas iniciados con el curso lectivo de 2018 están dirigidos a estudiantes de décimo año, facilitados por profesores y profesoras de psicología y como una materia a parte (MEP, 2018).

Los programas han sido asociados por diversos grupos con la llamada "ideología de género": esta conceptualización no tiene una definición totalmente clara, sin embargo, grupos informales, aunque bien organizados, la relacionan con la teoría de género y con una noción absolutista de que el sexo biológico es total y completamente independiente de la identidad de género (Molina, 2010). Esta discusión atañe directamente a la población sexualmente diversa y apela a las nociones actuales de lo masculino y lo femenino, patologizando lo que se aparta de la dicotomía del sexo biológico masculino y del sexo biológico femenino. Debo clarificar que las afirmaciones anteriores se refieren a un extremo, donde las posturas ideológicas sobre estos temas cubren múltiples constelaciones de preocupaciones y razonamientos. Muchos de ellos, alimentados por el temor de

\section{(c) (i) (2)}

La Revista Estudios es editada por la Universidad de Costa Rica y se distribuye bajo una Licencia Creative Commons Atribución-NoComercial-CompartirIgual 3.0 Costa Rica. Para más información envíe un mensaje a revistaestudios.eeg@ucr.ac.cr. 
que se invada 0 se socave la propia libertad individual y colectiva, comprometiendo también los valores sociales.

Ahora bien, en estos temas no hay recetas sencillas ni explicaciones contundentes. Todo lo relacionado con lo identitario, sexual, afectivo, comunitario, espiritual y social es y será una amalgama de complejidades a las que hay que acercarse con respeto, valor e inteligencia. En ese panorama complejo, el objetivo de este artículo no es ofrecer posturas ni respuestas, sino señalar el desafío para establecer espacios seguros para un diálogo necesario y a la vez difícil. Tan provocativo se ha vuelto besar como rezar. Más que provocaciones, se hace necesario generar espacios seguros y restaurativos en los que se puedan reconocer las diversas necesidades de todas las partes involucradas.

Fervor por Derechos Humanos. Fervor por la fe.

El clima de las elecciones presidenciales costarricenses generó fervor en la población, manifestado en los medios locales y nacionales, en las redes sociales y en manifestaciones comunitarias. La participación y compromiso de las personas involucradas, desde diversas posturas, tiene que ver con la defensa de elementos que consideran intrínsecamente valiosos, siendo un par de ejemplos la fe y los derechos humanos. No son las únicas cosas que se manifestaron o defendieron, pero son ejemplos ilustrativos de lo que se juega en una conversación en la que lo que está sobre la mesa son cosas afianzadas a la esensia de grupos e individuos. Ahora bien, eso no significa que el encuentro no sea posible.

Un ejemplo interesante de cómo grupos religiosos se han aproximado a este tema incluye la experiencia del Seminario Nacional Nuestra Señora de los Ángeles de Costa Rica. En el Seminario Nacional Nuestra Señora de los Ángeles, por más de 18 años se han impartido talleres anuales sobre sexualidad y afectividad, coordinados por el Dr. Gaston de Mézerville. La autora ha facilitado

\section{(c) (i) (2)}

La Revista Estudios es editada por la Universidad de Costa Rica y se distribuye bajo una Licencia Creative Commons Atribución-NoComercial-CompartirIgual 3.0 Costa Rica. Para más información envíe un mensaje a revistaestudios.eeg@ucr.ac.cr. 
talleres en el marco de estos procesos por más de doce años. El tema del género se ha abordado en los talleres de afectividad y sexualidad por más de una década, como se puede ver en este fragmento de la guía de mi taller particular. Se ha trabajado en grupos de discusión, dramatizaciones y debates. Se ha discutido su relevancia en la labor social. El fragmento dice así:

\section{Diferencia entre sexo y género}

Se realiza una introducción del tema en el que se explica la diferencia entre sexo biológico y rol social asignado por género. Se introduce el concepto de género, después de reiterar los conceptos trabajados el segundo día de taller. Entendemos género como aquellas características socialmente asociadas según la persona sea varón o hembra. A estos conjuntos de características los nombraremos como "lo masculino" y "lo femenino".

En esta parte se puede solicitar a los participantes que mencionen qué características se asocian a lo masculino (por ejemplo: valiente, no llora, no expresa sentimientos, es agresivo, violento, etc.) y a lo femenino (por ejemplo: sumisa, de la casa, no habla, etc.). (Guía de Taller para III de Filosofía: Reconstruyendo la Socialización Sexual de Manera Integral. Alvarado, C., 2004. Última revisión por De Mézerville y Oviedo, 2016, p. 17).

Cabe mencionar que este taller se ha impartido hace más de quince años, con buen recibimiento por parte de los seminaristas. Desde el año 2016, estos temas se reciben con aprehensión, no obstante la dinámica de la discusión libre y crítica ha permitido generar espacios constructivos y sensibles para la reflexión y

\section{(c) (i) (2)}

La Revista Estudios es editada por la Universidad de Costa Rica y se distribuye bajo una Licencia Creative Commons Atribución-NoComercial-CompartirIgual 3.0 Costa Rica. Para más información envíe un mensaje a revistaestudios.eeg@ucr.ac.cr. 
el aprendizaje. Debido al entorno social polarizado, cuando mi colega y yo introducimos el tema de "masculinidades", los seminaristas contestan con comentarios en la línea de "así como lo presentan ustedes es muy valioso, pero estos temas son peligrosos". Perciben el peligro en términos de una invasión a su sistema de creencias.

Aún así, los talleres de afectividad y sexualidad son valorados y bien recibidos en el Seminario. Estas iniciativas han sido posibles gracias a un abordaje abierto a la reflexión y a la observación sensibilizada de las realidades humanas y comunitarias. La experiencia ha demostrado que una reflexión crítica y abierta sobre estos temas fortalece habilidades para la vida, para el liderazgo y para una cultura de paz. La gran pregunta a la que debe responder el debate sobre la educación sexual desde las aulas costarricenses es: ¿estamos ofreciendo a nuestra niñez y juventud el ambiente más propicio para que todos y todas puedan desarrollar al máximo sus talentos y potencialidades, tanto desde lo individual como en su proyección a la sociedad?

\section{Una prospuesta integradora}

En este clima político adverso y sobre el contexto de la educación sexual para adolescentes costarricenses, tres profesionales en psicología, a saber, el Dr. Gaston de Mézerville, la M.Sc. Margarita Murillo y la autora de este artículo establecimos una reunión exploratoria para definir los elementos claves que se hacen necesarios para fomentar el sano desarrollo sexual de la población joven costarricense. Tras su elaboración, se le presentó a siete profesionales más para recabar sus comentarios y observaciones. Una vez establecida la versión final del escrito, los diez psicólogos y psicólogas dimos nuestra adhesión al comunicado, el cual se difundió a través de las redes sociales. El comunicado se transcribe a continuación:

\section{(c) (i) (2)}

La Revista Estudios es editada por la Universidad de Costa Rica y se distribuye bajo una Licencia Creative Commons Atribución-NoComercial-CompartirIgual 3.0 Costa Rica. Para más información envíe un mensaje a revistaestudios.eeg@ucr.ac.cr. 
PROPUESTA INTEGRADORA

SOBRE LA EDUCACIÓN SEXUAL EN COSTA RICA

Como psicólogos costarricenses, con experiencia en el campo educativo sobre la sexualidad desde una perspectiva humanista integral, nos preocupa mucho la polarización que vive el país en relación con el tema de la sexualidad. Día a día constatamos reacciones de miedo, desunión e intolerancia, que nos perjudican a todos como sociedad. Por tal razón, de manera personal y no en representación de las instituciones para las que trabajamos, hemos querido buscar puntos de unión desde un enfoque con el que la mayoría de la ciudadanía pueda coincidir. Para esto proponemos diez principios claves sobre la educación sexual que requieren nuestros niños, niñas y jóvenes:

1. La sexualidad es esencial en la vida humana y está estrechamente unida al afecto.

2. Los seres humanos necesitan ser educados para crecer y vivir saludablemente la sexualidad.

3. En el seno de la familia, de la comunidad y del sistema educativo se debe trabajar conjuntamente y con mutua colaboración para el logro de este propósito de educación sobre sexualidad.

4. Una adecuada educación sexual debe crear conciencia y armonizar entre las dimensiones corporal, psicológica y valorativa, además de adaptarse a las necesidades y vulnerabilidades de cada comunidad y grupo social.

5. Cuando no hay formación ni acompañamiento, las consecuencias incluyen la violencia en diferentes contextos y un mal manejo de sí mismo, lo que repercute en violencia intrafamiliar, conductas promiscuas, deslealtad a la pareja, incesto, embarazo adolescente,

\section{(c) (i) $(\mathcal{B})(0)$}

La Revista Estudios es editada por la Universidad de Costa Rica y se distribuye bajo una Licencia Creative Commons Atribución-NoComercial-CompartirIgual 3.0 Costa Rica. Para más información envíe un mensaje a revistaestudios.eeg@ucr.ac.cr. 
abusos, comportamientos autodestructivos, dependencia de la pornografía y otras adicciones sexuales.

6. Por el contrario, se ha comprobado que la educación y el conocimiento integral sobre la sexualidad ayudan a prevenir las relaciones abusivas o impropias, el inicio precoz de la actividad sexual, las enfermedades de transmisión sexual y los embarazos no deseados.

7. Es necesario promover una cultura de paz y de respeto entre todas las personas, caracterizada por el diálogo abierto y la promoción de ambientes libres de violencia, en los que se practique la tolerancia y la incorporación de todos, comprendiendo las características de cada persona, su historia familiar, religión, orientación sexual e identidad sexual.

8. Para una sexualidad sana, cada persona debe vivir un proceso de autoconocimiento en los ámbitos físico y emocional, así como elaborar un proyecto de vida constructivo que incorpore el amor y los valores en las relaciones de afecto.

9. Las personas necesitan de espacios seguros, respetuosos y educativos para conversar sobre su sexualidad, donde puedan ser escuchadas y apoyadas, además de obtener información veraz, científica y acorde a la edad, así como buenos modelos para vivir y trasmitir a otros.

10. La vivencia sana de la sexualidad debe incluir la promoción de una buena autoestima, que lleve a la persona a actuar con responsabilidad en su proyecto de vida, crecer en la capacidad de compromiso y de entrega al otro, así como de manifestarse con integridad en cuanto a sus más profundas convicciones.

\footnotetext{
(c) (i) (2)

La Revista Estudios es editada por la Universidad de Costa Rica y se distribuye bajo una Licencia Creative Commons Atribución-NoComercial-CompartirIgual 3.0 Costa Rica. Para más información envíe un mensaje a revistaestudios.eeg@ucr.ac.cr.
} 
Por lo tanto, tomando como referencia estos principios que mayoritariamente compartimos, proponemos las siguientes acciones para ponerlos en práctica:

- Avalar el acuerdo del Colegio Profesional de Psicólogos de Costa Rica de que es importante que la educación sexual se imparta en el sistema educativo, sin dejar de lado la educación que debe ofrecerse fundamentalmente en el seno familiar y tomando en consideración los valores y creencias que caracterizan a nuestra nación, desde una perspectiva educativa y de sensibilidad cultural.

- Considerar que la educación sexual es un tema de constante diálogo, reflexión y revisión, proyecto en el que deben participar de forma continua las entidades gubernamentales, las familias, las comunidades y las instituciones relacionadas con esta temática.

- Insistir en la responsabilidad que tienen las personas en posiciones de liderazgo de convocar a representantes de los distintos sectores para que, respetando sus diferencias de pensamiento y a partir del programa educativo actual, se establezcan espacios de retroalimentación y mediación que contribuyan a sugerir aquellos ajustes de contenido o metodológicos que resulten pertinentes.

- Creer en la capacidad que poseen las personas para superar el miedo, la polarización y la crítica negativa, mediante la escucha mutua y la unión que nos permitan reconocer el talento, generosidad y compromiso de nuestro pueblo para enfrentar satisfactoriamente estos difíciles retos que hoy nos agobian, como seres humanos, como familias y como instituciones comunitarias y gubernamentales, para el bien del país y de nuestros niños, niñas y jóvenes.

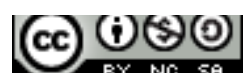

La Revista Estudios es editada por la Universidad de Costa Rica y se distribuye bajo una Licencia Creative Commons Atribución-NoComercial-CompartirIgual 3.0 Costa Rica. Para más información envíe un mensaje a revistaestudios.eeg@ucr.ac.cr.
} 
Firmamos:

- Claire de Mézerville López, psicóloga y Máster en Educación, representante regional del Instituto Internacional de Prácticas Restaurativas en Latinoamérica

- Angie Michelle Salas Monney, Psicóloga.

- Daniel Flores Mora, exdirector de la Escuela de Psicología de la UCR y expresidente del Colegio Profesional de Psicólogos de CR

- Margarita Murillo, psicóloga, sexóloga y consultora internacional, participante en la primera etapa del Programa para Educación Sexual del MEP

- René Sandoval, psicólogo del Colegio de Naciones Unidas United World College

- María Ramírez, psicóloga y sexóloga, profesora del curso de Sexualidad en Psicología de la U Católica

- Álvaro Campos Guadamuz, psicólogo, sociólogo y sexólogo, presidente del Instituto de Masculinidad-WËM

- Gastón De Mézerville Zeller, psicólogo y coordinador de los Talleres de Sexualidad y Afectividad del Seminario Nacional en Paso Ancho

- Janina Córdoba Ovares, psicóloga y sexóloga, facilitadora en la Comunidad Pas ("Perdonados para Amar y Servir")

- Juan Carlos Oviedo, psicólogo y profesor en colegios de Educación Secundaria

(De Mézerville, 2018. Tomado del Perfil Público de Facebook de Claire de Mezerville, 26 de febrero de 2018).

\section{cc) (i) (2)}

La Revista Estudios es editada por la Universidad de Costa Rica y se distribuye bajo una Licencia Creative Commons Atribución-NoComercial-CompartirIgual 3.0 Costa Rica. Para más información envíe un mensaje a revistaestudios.eeg@ucr.ac.cr. 
El objetivo de esta propuesta es fomentar espacios seguros y restaurativos para el diálogo, aunque éste sea difícil. Un espacio seguro para el diálogo es aquel en el que todos y todas tengan la posibilidad de participar en un ambiente seguro y respetuoso. Un espacio restaurativo es aquel que fomenta la participación de todos y todas en relaciones humanas caracterizadas por alto control y alto apoyo.

Ahora bien, el objetivo de la propuesta integradora no puede ser ni será el establecer consensos absolutos. No obstante, el establecer premisas como las anteriores como bases de alta prioridad puede contribuir a generar un clima de incipiente confianza entre representantes de posturas diversas: saca el tema del ámbito de "ganar o perder", relacionado con la polarización política e ideológica y lo lleva al ámbito de las soluciones. Tenemos un objetivo común: establecer un ambiente apropiado para el óptimo desarrollo de niños, niñas y adolescentes, el cual es un objetivo de servicio.

Finalmente, más que los partidismos identitarios, se trata de los niños, niñas y adolescentes de nuestro país. Cómo ofrecerles el control y apoyo que necesitan para desarrollarse con libertad, seguridad y equidad. Sobre este último concepto, es relevante asociarlo con la descripción de Pollock (2017), cuando define la equidad como las variadas acciones y respuestas ante la siguiente pregunta: ¿estamos haciendo todo lo que podemos hacer para que todos y cada uno de los niños, niñas y adolescentes puedan crecer sanamente y desarrollar al máximo su potencial? La Educación sexual es un elemento clave para el crecimiento adecuado y el desarrollo de las individualidades, de los vínculos sanos, así como de comunidades equitativas y saludables.

¿Es posible el consenso?

Debido a que el tema sobre cómo educar a menores de edad sobre afectividad y sexualidad atañe a elementos vitales para las personas (amor, 
tradición, salud, placer, violencia, solo por mencionar algunos) y se circunscribe a un contexto histórico tan polarizado, debo decir que considero humildemente que el consenso es imposible. Comenzando por el tema de educación sobre anticonceptivos y planificación familiar, siguiendo por los principios y dogmas religiosos con los que personas y grupos se han comprometido, continuando con el tema de la diversidad sexual y la lucha contra el acoso homofóbico, solo por mencionar además lo referente a la lucha contra la desigualdad de género (con su mortífera estela de violencia), existen principios que no serán negociables para las diferentes partes. Las conversaciones se vuelven volátiles y ciertos temas, como el aborto, se convierten en un campo minado de trampas hacia el discurso violento y agresivo. Haríamos mal, sin embargo, en evadir la conversación con tal de mantener la paz. Por el contrario, la paz se construye cuando aprendemos a generar los espacios seguros en los que sea posible hablar sobre los temas más difíciles. Eso sí, el consenso, aunque deseable, no puede ser la meta de la conversación. ¿Cuál es la meta entonces? Quizás sea ganar una mayor comprensión sobre las necesidades de todas las partes involucradas; identificar la humanidad común y los puntos de acuerdo, por pequeños que sean. $Y$ construir a partir de ahí.

Existen liderazgos estatales y comunitarios que podrían asumir el abrir estos espacios. En una nota aparte, la Asamblea Legislativa de Costa Rica, este 1 de mayo de 2018, escogió como presidenta del congreso a una abogada especialista en mediación y resolución alterna de conflictos. ¿Será que los liderazgos que se relacionen con éste tema puedan abrir conversaciones dirigidas a la mediación y al diálogo restaurativo? Quizás mediante la aplicación de Círculos Restaurativos (Costello, Wachtel y Wachtel, 2010; Pranis, 2006). Es posible que el Círculo sea el medio por excelencia por el cual todos y todas las participantes de un diálogo sobre temas tan volátiles cuenten con la estructura para participar en un clima seguro y para comprometerse a escuchar a sus contrapartes.

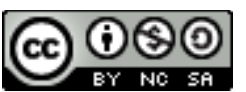

La Revista Estudios es editada por la Universidad de Costa Rica y se distribuye bajo una Licencia Creative Commons Atribución-NoComercial-CompartirIgual 3.0 Costa Rica. Para más información envíe un mensaje a revistaestudios.eeg@ucr.ac.cr. 
Sean quienes sean los que asuman las riendas para tomar decisiones en este respecto, contarán, cada quién en su trinchera -odiosa metáfora, pero aplicable- con las amenazas de un grupo importante de detractores. No obstante, si los principios comunes dichos arriba se defienden, se promueven y se colocan sobre la mesa del encuentro, la negociación será posible. Personalmente, mantengo un optimismo reservado. Aún en medio de la polarización, las identidades partidarias y las pasiones del momento histórico, muchas personas sobrevuelan los algoritmos de las redes sociales o del seguimiento a ciegas de posturas extremas. Somos muchos los que queremos saltar esa cerca divisoria y decir: tenemos mucho qué perder aquí. Es nuestra población joven. Nosotros somos los adultos y nos necesitan. Mejor entendámonos mejor, aunque no coincidamos en todo.

Una palabra clave: externalización

Un elemento importante será la externalización del desacuerdo. White (2007) habla sobre la externalización como la capacidad de separar al sujeto de sus acciones. Según Freedman \& Combs (1996), la externalización consiste en separar el asunto de la persona misma. La externalización se alimenta de la convicción de que el problema es algo que opera, impacta o afecta la vida de la persona, pero es algo aparte y diferente de la persona en sí. Así, por ejemplo, en lugar de decir que una persona es prejuiciosa o ignorante, hablamos de que esa persona está siendo afectada por un prejuicio o no tiene la información que necesita. Los autores insisten en que esto no es únicamente un truco lingüístico: es una manera de ver el mundo y las relaciones humanas. Nos permite reconocer el valor intrínseco de todo individuo, superar los juicios de valor y a su vez devolverle a las partes la responsabilidad para participar en las conversaciones.

El contexto polarizado se ha caracterizado por una variedad insultos. Aún si el interlocutor considera que tiene las bases para justificar su enunciado, el insulto, 
incluso el sutil y disimulado, entorpece el diálogo. El insulto puede ser individual o referirse a causas o grupos enteros. El concepto de "Ideología de Género" es un ejemplo. Si los que defendemos ciertas causas, luchas o proyectos resentimos este concepto de "Ideología de Género", el cual es desplegado por los detractores de alguna o varias causas relacionadas con los temas mencionados aquí, la insistencia en el mismo va a cerrar el diálogo, al igual que lo haría el que uno diga que para hablar de comunidades de fe, se utilizarán conceptos como "intolerancia" u "homofobia". Igual que dos personas no podrán encontrarse si siguen llamándose por sus apodos, la única forma de que el diálogo sea posible consistirá en aprender los verdaderos nombres de las partes que participan en esta conversación y procurar escucharse.

Claro, en la libertad de cada quién está el decir: "lo digo a como veo que es, se ofenda quién se ofenda". Yo propongo esto: buscar la forma de reconocernos mutuamente no es necesariamente acomodarnos. A veces es necesario ganar una comprensión mayor sobre lo que le preocupa a quién está al otro lado de la trinchera ideológica. En estos tiempos de posturas extremas, por volvernos cada vez más radicales, terminaremos con la cabeza metida en la tierra. Un siglo XXI lleno de avestruces.

Un espacio seguro para el diálogo será posible a partir de la externalización de esos asuntos que nos separan, una externalización que nos permita confrontarnos con nuestra humanidad común. Quizás a través de un Círculo u otro tipo de estructura, que ofrezca a todos y todas, la oportunidad de expresarse, que tenga apertura a la expresión de emociones y que se oriente hacia las soluciones, a la vez que comprometa a todos a autorregularse para no interrumpirse mutuamente.

\section{(c) (i) (2)}

La Revista Estudios es editada por la Universidad de Costa Rica y se distribuye bajo una Licencia Creative Commons Atribución-NoComercial-CompartirIgual 3.0 Costa Rica. Para más información envíe un mensaje a revistaestudios.eeg@ucr.ac.cr. 
Un abordaje culturalmente sensible

Uno de los puntos de la propuesta integradora firmada por el equipo de 10 psicólogos y psicólogas incluyó la importancia de tomar en cuenta los "valores y creencias que caracterizan a nuestra nación" (de Mézerville, 2018 -Propuesta citada arriba-) desde una perspectiva de sensibilidad cultural. Es importante hacer notar en esta sección que no se está defendiendo la postergación de la defensa de los derechos de las personas por mantener un tradicionalismo. Toda acción que atente contra la integridad de un ser humano debe defenderse sin demora y con valentía. Un abordaje culturalmente sensible no significa evadir el conflicto. Significa enfrentarlo con empatía, justicia, seguridad e inteligencia. A su vez, significa reconocer que la implementación de cualquier programa, debe contextualizarse a la realidad cultural de cada población, reconociendo sus principales necesidades.

La Educación Sexual desde la implementación de los Programas del Ministerio de Educación Pública haría bien en integrar una red de apoyo comunitaria, capaz de incorporar propuestas y metodologías que integren a padres y madres de familia, comunidades de fe, así como enlaces interinstitucionales con las instancias de acogida a mujeres de las diversas comunidades. Esto puede sonar utópico, pero no es imposible.

Se hace relevante retomar los principios del proceso justo propuesto por Kim \& Maughbourne (2003), aplicables a las comunidades: las diferentes partes cooperarán con un sistema en tanto se mantengan los principios de un proceso justo. Estos principios son: (1) participación activa, (2) explicación por parte del liderazgo sobre las razones de lo que se implementa y (3) claridad de expectativas para todos. Si existe una expectativa clara de que el objetivo de una red de apoyo para los programas del MEP no es la de alcanzar consenso en todo, sino la participación activa y cooperativa de todas las partes en un proceso justo, que se acoja al liderazgo democráticamente elegido -susceptible de cambio en elecciones 
locales y nacionales-, la interacción participativa y activa será posible. La interacción participativa disolverá poco a poco la polarización, ya que la cooperación mutua es el mejor ingrediente para enfrentar y superar suspicacias.

Más allá de la vergüenza y el miedo

Mucha de la resistencia existente está relacionada con el temor y la vergüenza que se asocian con lo relacionado a la sexualidad. Según la teoría de los afectos de Tomkins (Costello, Wachtel y Wachtel 2010) manejar los afectos relacionados con el conflicto y la polarización no se circunscribe únicamente al ambito de lo racional o a la capacidad individual para el procesamiento de la información. Involucrará necesariamente importantes elementos emotivos, como lo son la vergüenza, la vulnerabilidad, el riesgo y el miedo. Es difícil hablar sobre temas relacionados con sexualidad. Entre más vergüenza, menos se habla, pero entre menos se habla, la vergüenza aumentará (Kaseke, 2010).

En este sentido, es importante visibilizar las necesidades comunitarias relacionadas con la educación sexual de la población adolescente, comenzando por observar las particularidades de cada cantón, relacionadas con embarazo adolescente, enfermedades de transmisión sexual, denuncias por cyber byllying, denuncias por acoso sexual, así como temas relacionados con incesto y relaciones impropias. Todos estos son temas difíciles que necesitamos enfrentar desde las ciencias sociales junto con el involucramiento comunitario.

Un ejemplo muy interesante de un abordaje comunitario sobre el tema del abuso sexual se dio en Zimbabwe, en el cual trabajadores comunitarios locales desarrollaron una metodología culturalmente apropiada para explorar las respuestas de niños, niñas y jóvenes ante ataques sexuales. El objetivo era poder abordar el tema y educar a la población sin generar espacios de autorrevelación individual que los vulnerabilizaran, los revictimizaran o los pusieran en riesgo. En otras experiencias de esta localidad, comunidades similares evadían el tema y 
preferían no asistir a talleres sobre esto. En esta experiencia, el trabajo se hizo con toda la comunidad en conjunto y otorgando el protagonismo a los niños, niñas y jóvenes, a través de una metodología de externalización, en la cual uno de los funcionarios representó el rol de "abuso sexual". Así, los niños, niñas y jóvenes le hacían preguntas al "abuso sexual", el cual les respondía de manera pedagógica y adecuada a su edad. Luego la población pudo expresarle directamente cómo él afectaba a su comunidad. Pudieron, juntos, ponerse en su contra y resistirlo. Aunque en este taller se procuró mantener un tono relativamente liviano y divertido, la comunidad se involucró de forma activa. La comunidad pudo experimentar un sentimiento de mutua identificación al afirmar: "éste es un problema grave. Nos afecta a todos. Todos debemos hacer lo que podamos al respecto." De manera anecdótica, el autor menciona que ésta comunidad, tras esa experiencia, solicitó más talleres sobre este tema (Kaseke, 2010).

Es natural que hablar sobre temas que vulnerabilizan la salud, los derechos humanos y la fe de las personas sea difícil. Es intrínsecamente humano que haya miedo, vergüenza y recelo. Esos afectos, que podrían impulsarnos a la agresión, también responden a nuestra humanidad común, en la cual podríamos encontrarnos. El diálogo no ocurrirá espontáneamente. El liderazgo apropiado, la generación de espacios seguros y medianamente estructurados, así como la voluntariedad de las partes son elementos indispensables. La participación activa de todos los principales actores sociales es absolutamente necesaria.

La cultura de paz puede construirse a través de esta experiencia. Quizás este clima volátil y polarizado logre sacar lo mejor de nosotros mismos como costarricenses. Quizás apele a nuestra valentía, la cual nos impulsará a poner manos a la obra. Quizás estas conversaciones llenas de tensión sean para bien y nos lleven a ofrecer algo aún mejor a nuestra población menor de edad. Aún más importante: necesitamos preguntarle a la población adolescente e involucrarles en el proceso. Ellos y ellas tienen algo qué decir sobre sus necesidades en materia

\section{(C) $\odot \Theta \odot$}

La Revista Estudios es editada por la Universidad de Costa Rica y se distribuye bajo una Licencia Creative Commons Atribución-NoComercial-CompartirIgual 3.0 Costa Rica. Para más información envíe un mensaje a revistaestudios.eeg@ucr.ac.cr. 
de educación sexual. ¿Se nos había ocurrido que ellos y ellas deberían tener una participación activa y protagónica en esta conversación?

En la medida en la que podamos rescatar que esta conversación es urgente porque apela a temas de salud pública y a temas relacionados con la integridad física inmediata de las personas, será posible ir más allá de la guerra civil ideológica para retomar la prioridad de esta discusión: como adultos tenemos la tarea impostergable de generar un ambiente sano para las personas menores de edad. Nos toca a nosotros. Debemos resolver esto. Ellos y ellas deberían poder confiar en que su bienestar es nuestro principal interés.

\section{Referencias}

Costello, B., Wachtel, J. \& Wachtel, T. (2010). Manual de Prácticas Restaurativas para docentes, responsables de la disciplina y administradores de instituciones educativas. Bethlehem, Pennsylvania: International Institute for Restorative Practices.

Corte Interamericana de Derechos Humanos (2017). Opinión Consultiva OC-24/17 de 24 de noviembre de 2017 solicitada por la República de Costa Rica. IDENTIDAD DE GÉNERO, E IGUALDAD Y NO DISCRIMINACIÓN A PAREJAS DEL MISMO SEXO. Recuperada el 1 de mayo de 2018. Disponible en: http://www.corteidh.or.cr/docs/opiniones/seriea 24 esp.pdf

De Mézerville, C., Murillo, M. y de Mézerville, G. (2018). Propuesta Integradora sobre la Educación Sexual en Costa Rica. Tomado de Facebook, perfil de Claire de Mézerville. 26 de febrero de 2018. Disponible en: https://www.facebook.com/claire.demezerville/posts/10156248413813086

De Mézerville, C. y Oviedo, J. (2016). Guía de Taller para Tercero de Filosofía: Reconstruyendo la Socialización Sexual de Manera Integral. Basado en Alvarado, 2004. Guía de Trabajo no publicada. Seminario Nacional Nuestra Señora de los Ángeles.

\section{(c) (i) (2)}

La Revista Estudios es editada por la Universidad de Costa Rica y se distribuye bajo una Licencia Creative Commons Atribución-NoComercial-CompartirIgual 3.0 Costa Rica. Para más información envíe un mensaje a revistaestudios.eeg@ucr.ac.cr. 
Freedman, J., \& Combs, G. (1996). Narrative therapy: The social construction of preferred realities. New York, NY: W.W. Norton.

Harris, S. (Productor). (2018, Febrero 18). Networks, Power and Chaos. A conversation with Niall Ferguson. (Audio Podcast). Recuperado de: https://samharris.org/podcasts/117-networks-power-chaos/

Harris, S. (Productor). (2018, Enero 22). Politics and Sanity. (Audio Podcast).

Recuperado de: https://samharris.org/podcasts/114-politics-and-sanity/

Kaseke, S. (2010). Standing together on a Riverbank: Group conversations about sexual abuse in Zinbabwe. The International Journal of Narrative Therapy and Community Work. 4: 42-44

Kim, W.C., \& Mauborgne, R. (2003, January). Fair process: Managing in the knowledge economy. Harvard Business Review, 81(1), 127-136.

Ministerio de Educación Pública (2017). Programa de Estudio de Afectividad y Sexualidad Integral. Tercer Ciclo. Recuperado el 1 de mayo de 2018. Disponible en: http://cse.go.cr/sites/default/files/afectividad y sexualidad integral iii ciclo 2017.pdf

Molina Brizuela, Y. (2010) Teoría de Género. Contribuciones a las Ciencias Sociales, octubre 2010. Recuperado el 1 de mayo de 2018. Disponible en: www.eumed.net/rev/cccss/10/

Pranis, K. (2006). Manual para facilitadores de Círculos. San José: CONAMAJ.

Pollock, M. (2017). Schooltalk: Rethinking what we say about and to students every day. New York: New Press.

Sistema Costarricense de Información Jurídica (SCIJ). (2018). Política Poder Ejecutivo para erradicar de sus instituciones discriminación población LGBTI. Procuraduría General de la República. Recuperado el 1 de mayo de 2018.

en: http://www.pgrweb.go.cr/scij/Busqueda/Normativa/Normas/nrm texto compl

\footnotetext{
(c) (i) (9) (2)

La Revista Estudios es editada por la Universidad de Costa Rica y se distribuye bajo una Licencia Creative Commons Atribución-NoComercial-CompartirIgual 3.0 Costa Rica. Para más información envíe un mensaje a revistaestudios.eeg@ucr.ac.cr.
} 
Revista Estudios, (37), 2018.

Diciembre 2018-Mayo 2019

ISSN 1659-3316

eto.aspx?param $1=$ NRTC $\&$ nValor $1=1 \& n$ Valor $2=84295 \& n V a l o r 3=108696 \&$ str TipM=TC

Vizcaíno, I. (2017). Cambios en Programas del MEP: Hay que hablar de la diversidad sexual y género. Periódico La Nación. 10 de abril de 2017. Recuperado el 23 de marzo de 2018. Disponible en: https://www.nacion.com/el-pais/educacion/cambios-en-programas-del-mephay-que-hablar-de-la-diversidad-sexual-ygenero/FFKL7NPN3ZCAXNRGKSCCT46ZPQ/story/

Wachtel, T. (2013). Defining Restorative. International Institute for Restorative Practices.

White, M. (2007). Maps of narrative practice. New York, NY: W.W. Norton. 